\title{
Singaporean Malay-Muslim Women's Lifestyle Habits and Attitudes towards Health
}

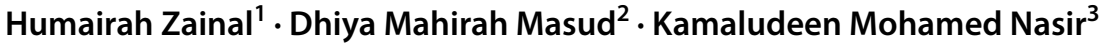

Accepted: 16 August 2021 / Published online: 20 August 2021

(c) The Author(s), under exclusive licence to Springer Nature B.V. 2021

\begin{abstract}
This article examines how the intersections of Singaporean Malay-Muslim women's religious and gendered subjectivities influence their lifestyle habits and health attitudes. It explores the gaps between their practices, perspectives and discourses that discuss Islam's relevance in health educational programmes. Individual semistructured interviews with 19 local women of diverse social backgrounds show that while Islam is influential in their health conceptions, this is limited to the selfinternalisation of theologically-based discourses. Discussions on how positive gender relations based on Islamic values can contribute to women's health outcomes are lacking in their narratives, existing academic literature and public discourses. A comprehensive approach to leveraging religious concepts in advocating good health for Muslims should also include women's empowerment and improvement of gender relations.
\end{abstract}

Keywords Malay-Muslim women $\cdot$ Lifestyle $\cdot$ Health $\cdot$ Islam $\cdot$ Gender relations · Singapore

Humairah Zainal

humairahzainal@gmail.com

Dhiya Mahirah Masud

dhiyamahirah@gmail.com

Kamaludeen Mohamed Nasir

kamaludeen@ntu.edu.sg

1 Health Services Research Unit, Singapore General Hospital, Singapore, Singapore

2 Health Services Research and Evaluation, SingHealth Regional Health System, Singapore,

Singapore

3 Division of Sociology, School of Social Sciences, Nanyang Technological University,

Singapore, Singapore 


\section{Introduction}

This article examines how Islam may be manifested in the lifestyle habits and health perspectives of Muslim women in Southeast Asia through the case study of Singaporean Muslim women's health narratives. While there have been studies on the health conditions, perspectives, daily habits and utilisation of healthcare services among Muslim women from the United States, Middle East, South Asia and elsewhere around the globe (Ahaddour \& Broeckaert, 2018; Bahar et al., 2005; Rai, 2015; Vu et al., 2018), few have focused on those of Muslim women in Southeast Asia. Thus, based on interviews with 19 Muslim women from Singapore, this article examines how the intersections of religious and gendered subjectivities may influence lifestyle habits and attitudes towards health.

Muslim women, particularly those of Malay ethnicity, form the focus of the study given the strong entwinement between Islam and Malay identity in Singapore. Singaporean Muslims are primarily Sunnis who practise the Shafi'i school of thought (Abbas, 2012; Kiong, 2008). This article focuses on the narratives of Sunni Muslims given their dominance in Southeast Asia. The present study explores the gaps between local Muslim women's perspectives and practices, as well as public and academic discourses that discuss Islam's relevance in health educational programmes. The article postulates that any barriers that occur at the intersections of religious and gendered sensibilities would prevent them from optimising positive health outcomes. It argues that a comprehensive approach to leveraging religious concepts in advocating good health for Muslim communities worldwide should also take into consideration fundamental values of Islam, which include compassion and respect for women. Findings from our study bears important implications on faith and gender-based health promotion interventions that contribute to the well-being of Muslims.

\section{Islam, Women and Health}

Much has been written on the role and relevance of Islam in shaping lifestyle practices and outlining guidelines for cures and therapies (for example, AboulEnein, 2016; Koenig \& Al Shohaib, 2014; Rajaram \& Rashidi, 2003).

Major themes often detail the code of ethics informed by the Quran and Hadith as they relate to healthcare including the rationale behind avoiding products that are prohibited for consumption, the actions of and advice by Prophet Muhammad for maintaining good health and curing illnesses, and the influence of healthy social relationships on mental and physical health (Aboul-Enein, 2016; Koenig \& Al Shohaib, 2014; Rajaram \& Rashidi, 2003). A narrative study by AboulEnein (2016), which examines health-promoting verses in the Quran, identifies 28 verses that discuss diet, personal hygiene, alcohol abstention and the importance of a healthy lifestyle. Other works have discussed the role of imams (religious leaders) and practitioners of Islam in encouraging healthy behaviours through 
scripture-based messages in sermons, assisting healthcare decisions for Muslims, advocating for Muslim patients' needs and performing religious rituals around illnesses and life events (for instance, Zakaria \& Zainal, 2017; Padela et al., 2011; Vu et al., 2018).

These studies also show that the process of delivering religiously laden messages to promote desirable healthcare behaviours, as well as framing certain healing practices as Islamically-driven, do not go uncontested. For instance, while getting healthcare institutions and providers to partner with imams and mosques have the potential for much benefit, there is also room for ethical conflict (Padela et al., 2011). This is largely due to lack of medical knowledge, understanding of the healthcare system, and the necessary skills to navigate complex healthcare services on the part of some imams. Such gaps call for greater institutional support and a delineation of core competencies for Muslim chaplains in the realm of Islamic law and ethics (Padela et al., 2011). Furthermore, given the heterogeneity of Muslim communities, healing practices deemed Islamic by some may not be so for others. To illustrate, the practice of shamanism within traditional Malay medicine may be perceived as one that is based on Islamic principles by some Malays but condemned by others due to the elements of polytheism and indigenous superstitions that may be embedded in the practice, all of which go against the tenets of Islam (Zakaria \& Zainal, 2017; Zainal, 2012). This explains why some shamans have co-opted Islamic concepts and discourses into their practice in order to legitimise and strengthen their position (Zakaria \& Zainal, 2017).

Although insightful, the literature on health and illness from an Islamic perspective have largely been focused on the physical, psychological and spiritual aspects of health and illness within individual selves (Aboul-Enein, 2016; AlKhayat, 1997; Ashy, 1999; Tober \& Budiani, 2007). These include a 1997 report published by the World Health Organization (WHO) that discusses the fiqh of health. Fiqh refers to knowledge of practical Islamic rulings as deduced from detailed statements and religious texts (AlKhayat, 1997). Even though the WHO has expanded the definition of health to encompass "a state of complete physical, mental and social well-being and not merely the absence of disease or infirmity" (World Health Organisation, 2020), there are still gaps in addressing the health needs of certain communities. These include a holistic approach to tackling women's health issues. As Dr Ala Alwan, WHO Regional Director for the Eastern Mediterranean highlighted, much emphasis had been placed on reproductive health issues while ignoring the gendered conditions and root causes of ill health among women (World Health Organization, 2013). Studies have also shown that women's ability to follow a healthy lifestyle is shaped by the socio-cultural context of their lives (del Mar García-Calvente et al., 2012; Razee et al., 2010). This article contends that the gendered social environment in which women's health conditions are embedded need to be analysed too.

Furthermore, even though community solidarity forms the central tenets of Islam, they are seldom discussed or utilised for the health benefits of Muslims. Although the 1997 WHO report contains references to this concept, it falls short of explaining how they are relevant or applicable to the daily lifestyle experience of Muslim communities (AlKhayat, 1997). This article interrogates if a holistic approach to leveraging Islamic concepts on health can be achieved by exploring the gaps between 
existing Islamic health discourses and Singaporean Malay-Muslim women's lifestyle habits. It does so through an ethnographic approach that uncovers their perspectives towards these discourses as well as the activities they engage to improve their health. This article seeks to contribute to the body of literature on health by incorporating women's voices in research. It does so for a few reasons. First, the fatwas (Islamic guidelines or opinions) on health have been mostly designed by men who may not necessarily understand the conditions and issues faced by women (The Straits Times, 2019). ${ }^{1}$ Second, global studies have proven that gender inequalities in healthcare, as well as the conflation of understanding between religious and cultural beliefs, significantly affect women's health and self-perceptions of their health (Bahar et al., 2005; del Mar García-Calvente et al., 2012; Palència et al., 2014). Within Singapore, this can be illustrated by Shaw et al.'s (2018) research on the influence of Islamic and Malay cultural beliefs on the uptake of breast cancer screening and genetic testing among Malay women. Their work shows that Islamic values, which prohibit women from revealing their body parts to non-mahram (non-spouse or immediate kin), act as barriers towards the women's participation in screening and testing. Therefore, by uncovering the gendered meanings of health among Singaporean Muslim women, this article contributes to a further understanding of the intersections of Islamic and gendered discourses on health that may not have received as much attention as spiritually-based arguments in the existing literature.

\section{Exploring Singaporean Malay-Muslim Women's Health Narratives}

Singapore is a multiracial country with the Chinese forming the majority of the population at $76 \%$. Malays, Indians and other ethnic groups constitute $15 \%, 7.5 \%$ and $1.5 \%$ of the rest of the population respectively (Singapore Department of Statistics, 2020a). This article focuses on the health conditions and perspectives of the Malays for a few reasons. First, ethnicity and religion are strongly intertwined in Singapore. Malays are the most homogenous community in religious terms, with $98.7 \%$ or 382,017 out of 386,968 of Malay Singaporeans aged 15 and older identifying themselves as Muslims (Singapore Department of Statistics, 2019). Given the considerable percentage of Malays within the Muslim population, and the limited scope of the article, this research has focused on their health narratives while acknowledging that those of other ethnicities within the Muslim community should also be addressed in future studies.

Second, various sources have often reported that local Malays suffer from a high incidence of chronic conditions in Singapore. According to the National Health Survey, which provides information on major non-communicable diseases such as stroke, diabetes and heart disease, about $24 \%$ of Malay adults are obese, compared with $16.9 \%$ of Indians and $7.9 \%$ of Chinese (Ministry of Health 2010). In 2017,

\footnotetext{
1 In Singapore, female scholars are involved in discussions on fatwas. However, female representation in the Fatwa Committee is lacking. It was only recently that Dr Rohana Ithnin was appointed as the first full female member of the Fatwa Committee (The Straits Times 2019).
} 
453.4 heart attacks per 100,000 people occurred among Malays compared to 447.0 among Indians and 187.4 among Chinese (National Registry of Diseases Office, 2019). In his National Day Rally in 2017, Prime Minister Lee Hsien Loong spoke at length about diabetes as one of the three key issues for Singapore (Prime Minister's Office Singapore, 2017). He quoted that 5 in 10 Malays and 6 in 10 Indians over 60 years of age have diabetes while only 2.5 in 10 Chinese suffer from the disease. In his speech that was delivered in Malay, Lee attributes the high incidence of chronic diseases amongst Malays to the 'unhealthy ingredients' in traditional Malay cuisines. Generally, the undesirable health outcomes of Malays are often associated with cultural norms and practices (Chang, 2010; Wong \& Toh, 2017).

This simplistic association between cultural habits and health outcomes has drawn sharp criticism from the Malay community, as it ignores socio-economic factors that contribute to conditions for poor health. As shown by studies from around the world, health disparities across different ethnic groups are largely attributed to socio-economic inequalities in society (for example, del Mar García-Calvente et al., 2012; Du Bois 1899; Tang \& Brown, 2008). Case in point, Tang and Browne's (2008) research on healthcare access for Aboriginal people in an urban centre in Canada illustrates how the ideological process of racialization intersects with the low socio-economic status (SES) of the Aboriginal people in ways that result in inequitable access to healthcare for such marginalised populations. Geographical locations brought about by poor SES have also exacerbated living conditions. In his seminal work, The Philadelphia Negro, which provides a detailed explanation of the 'negro problem' in America, W.E.B. Du Bois noted that the health of black Americans varied within Philadelphia by neighbourhood of residence. Specifically, death rates were higher in the Fifth Ward, which had the worst sanitation in the city, than the Thirtieth ward, which had "good houses and clean streets" (Du Bois [1899] 1967: 150-51). He also reported that black men had poorer health than black women and that the gender differences in health were larger for blacks than for whites due to their physical occupational environments (Du Bois 1899).

Within Singapore, Liang et al. (2018) study that compares health-related quality of life in five domains (mobility, self-care, usual activities, anxiety and pain) between residents living in rental flats (low-area SES) and those in owner-occupied blocks (high-area SES) has shown that staying in a low SES neighbourhood is characterised by a disproportionate number of residents coming from the minority race, more self-reported mental health issues, enhanced physical health problems and financial disadvantage in healthcare. Liang et al. (2018) postulates that the financial burden from supporting a large family unit may outweigh the greater social support for mental well-being associated with larger households, leading to an overall effect of greater anxiety. Other scholars, particularly Nazroo (1998), call for a more nuanced theorisation of ethnicity. In particular, Nazroo argues for an approach that recognises ethnicity as both structure and identity. This means that rather than just reducing explanations of health disparities between ethnic groups to class factors, we should also consider other elements of structural and systemic disadvantage faced by minority groups such as experiences of racism and discrimination. Beyond these, ethnicity should also be understood as an identity, one which is dynamic and contingent upon the cultural context of the particular ethnicity (Nazroo, 1998). 
Thus, these works have demonstrated that the link between poor health outcomes and cultural norms should not be accepted uncritically.

The third motivation behind exploring the health conditions of the Malays is driven by studies that have shown that there are stark gender differences in the health outcomes and lifestyle practices among the Malays. Sabanayagam et al.'s (2009) research, which explores the association between socioeconomic status and obesity in Singapore's Malay population, shows that obesity is more prevalent in women (65.1\%) than men (50.4\%). Gender differences are also reported in Ang's (2018) study, which considers if ethnicity accounts for gender differences in the social activities older Singaporean adults participate in, and the association between social participation and 4-year mortality. It reveals that Malay men are more likely than Malay women to engage in religious services and sports, reducing mortality risk (Ang, 2018). While congregational Friday prayer may explain Malay men's greater participation in religious services, no explanation was given for their higher rate of participation in sports, which warrants further examination.

Singapore represents a unique case study because public healthcare in the country is generally accessible to every citizen regardless of socio-economic background, ethnicity or gender. Despite some flaws within the healthcare system, such as barriers to healthcare access for poor elderly patients (Tan et al., 2019) and the relative difficulty to access private GP clinics (Khoo et al., 2014), there is no documented overt discrimination among Singaporeans based on ethnicity or income. In fact, various schemes and subsidies have been implemented to encourage healthcare access among the low income (Wee et al., 2014). Recently, the Ministry of Health $(\mathrm{MOH})$ has also introduced cost-effective treatments to ensure healthcare costs remain affordable for all (Ministry of Health, 2020). Moreover, rental flats for the low income are hardly concentrated in particular neighbourhoods. Rather, given Singapore's high urban density, they are scattered in the same precincts as owneroccupied flats (Wee et al., 2014). Primary care physicians are expected to be multilingual. Access to education and healthcare services are also not differentiated based on gender. Thus, this article analyses other under-explored factors that may have contributed to varied health outcomes among Singaporeans. It does this by examining how religious values may be intertwined with cultural norms and gendered subjectivities to influence the health conditions of Malay-Muslim women, which this article now turns.

\section{Research Methods}

\section{Procedure}

This study was based on individual semi-structured interviews with Malay-Muslim women of various social backgrounds. The participants were recruited through the researchers' networks, which include their friends and professional contacts, as well as the snowballing technique. A potential participant was considered eligible for interview if she was at least 21 years old, was a Singapore citizen or Permanent Resident and was identified as Malay by birth. Purposive sampling was used to recruit 
participants from three main age groups and income categories, namely, $20 \mathrm{~s}-30 \mathrm{~s}$, $40 \mathrm{~s}-50 \mathrm{~s}$ and 60 and above, as well as lower, middle and upper income. Low-income earners were those with a combined gross monthly household income of $\$ 3000$ or less, whereas those who fall within the middle category would earn between $\$ 3000$ and $\$ 6500$, and those in the high-income category earn more than $\$ 6500$ (Singapore Department of Statistics, 2019). Participants provided informed consent before taking part in the study.

\section{Data Collection}

Prior to each interview, participants completed a questionnaire on their demographics, medical history and self-assessment of five main aspects of physical health outlined by Singapore's Health Promotion Board (HPB). The latter encompass a wellbalanced diet, regular physical activities of about 150 min weekly, enough sleep and rest, regular health screenings and avoiding unhealthy habits such as smoking (MOH \& HPB, 2014). The questionnaire complemented the interview questions. The latter explored their self-assessed health literacy level, health outlook, and the influence of social networks and family members' health conditions on their lifestyle habits. While mental health constitutes part of a healthy lifestyle, physical health conditions form this article's focus. This article only examines habits aimed at illness prevention, health improvement and lifestyle maintenance instead of those targeted at illness management. It will not analyse the type of medications sought, or other actions taken to cure illnesses. The discussions were conducted by a research assistant in English and Malay and lasted approximately an hour. They were digitally recorded and transcribed verbatim.

\section{Data Analysis}

The three researchers read the transcripts independently and adopted a qualitative descriptive approach given the aim of achieving straight descriptions of phenomena without 'a conceptual or otherwise highly abstract rendering of data' (Sandelowski, 2000). The straightforward interpretation process also facilitated a relatively easy consensus between the researchers. Using qualitative content analysis, the researchers derived codes inductively from the data and exercised flexibility in the process of accommodating new insights about the data. References to gender and Islam that were both explicit and implicit were identified. Hence, beyond noting outward Islamic identity markers such as the Quran and Hadith and references to God, the less tangible ones including values and practices that are identifiable with Islam were also noted. Additionally, their narratives were examined against their gender identity, demographics, medical history and self-reported health to assess if there were any convergences or divergences between the former and latter. To ensure methodological rigour, the narratives were cross-checked with responses from the demographic questionnaires and were compared with findings from existing qualitative studies on how Muslim women discuss their health. In the reporting of findings, code identifiers based on the participants' income and age category were used when 
providing verbatim quotations to ensure anonymity. A summary of the categories is provided in Table 1 below. Each participant is assigned an alphabet and a number by the order in which the interview was conducted. For example, if a participant belongs to the low-income group, falls within the $20 \mathrm{~s}-30 \mathrm{~s}$ age category and was interviewed first, he or she will be assigned Code A1.

\section{Findings}

19 women aged between 22 and 70 years old participated in the study; eight were low-income earners, eight others were in the middle-income category and the remaining three were high-income. Their income category corresponded with their educational level. As the demographics have shown, the higher their income, the more educated they are in terms of academic and professional qualifications. 14 of them were married and five were never married. 13 were in full-time employment, two in part-time employment and four were unemployed. None had a domestic helper.

\section{Manifestations of Islam in Women's Health Perspectives}

The findings show that the women obtain their knowledge on healthy living from a variety of sources in both English and Malay. These include public talks by healthcare professionals and religious scholars, social media such as Facebook and YouTube, and mainstream media that include radio and television. Generally, the respondents do not face any difficulties when communicating about their medical conditions to their doctors. They are also aware of Islamic concepts pertaining to health. For instance, the notion of stewardship of one's body is often based on two interrelated concepts- the idea of the body as a 'loan' from God and as trust from God. Hence, as much as they believe that God predetermines and controls one's health outcomes, they find it important to take proactive measures in order to maintain good health and seek cures to illnesses. The excerpts below are representative of such views:

From an Islamic perspective, it is an amanah (responsibility) to take care of our body. As far as possible, we should be responsible for our own health. If we fall sick, we must make an effort to consult the doctor. (B2)

Table 1 Summary of Respondents' Age and Income Groups

\begin{tabular}{llll}
\hline $\begin{array}{l}\text { Age category/ Income } \\
\text { Group }\end{array}$ & Low & Middle & High \\
\hline $20 \mathrm{~s}-30 \mathrm{~s}$ & A & D & G \\
$40 \mathrm{~s}-50 \mathrm{~s}$ & B & E & H \\
$60 \mathrm{~s}$ and above & C & F & I \\
\hline
\end{tabular}


Maintaining good health is wajib (an obligatory religious duty commanded by

God). So, we must take good care of our health. (A2)

The women are also cognizant of what constitutes a healthy diet based on the guidelines provided by their religious texts and scholars. The following excerpts illustrate this point:

The notices at mosques serve as a useful reminder to Muslims. Some read: "Don't just be a Muslim. Be a good Muslim." This should also apply to our selection of food. We should not be consuming any type of food just because they are halal, but also those that are beneficial for our health. (B4)

We should go for healthier options and use healthy ingredients when preparing our meals. During Ramadan, we are advised to break fast with dates based on the Prophet's sunnah. Dates contain nutrients that are good for our body. (C2)

In addition, the women subscribe to the holistic approach advocated by Islam in maintaining well-being. This involves addressing not just their physical but psychosocial and spiritual needs as well. According to Rajaram and Rashidi (2003), this approach, in which health is realised through harmony and equilibrium between the body, the soul and the surrounding environment, is in contrast to the Western framework of healthcare, which is mainly predicated on mind-body dualism. Psychosocial needs encompass social interaction and care for other human beings as well as the environment whereas spiritual ones can be attained through prayers, fasting and performing good deeds. This integrated understanding of Islamic medicine and health, that one component cannot be readily separated from the others, are also deeply entwined with Malays' conceptualisation of the body. As Zakaria and Zainal (2017) have shown through their article on traditional Malay medicine in Singapore, the framework for Malay healing practices equally emphasise harmony between the mental and physical spheres, in which the health of the body cannot be separated from that of the mind and spirit. This explains why aspects of health such as mental and spiritual well-being are also emphasised by the respondents, as shared by A1 and $\mathrm{E} 3$ below:

My idea of a healthy lifestyle is having a well-balanced diet, exercising regularly and taking care of my mental health. If we keep stressing ourselves too much and putting pressure on ourselves, it can also be unhealthy and detrimental to our health. Activities like family bonding can help to improve our mental health because family support is also important. (A1)

Apart from eating healthily and in moderation, it is also important to have sufficient sleep because a lack of sleep would affect our mental health. Mental health is another important aspect of health that we need to take care of... calmness can also be achieved through performing our prayers. (E3)

As can be seen in the responses in this section, there is a significant understanding among Singaporean Malay-Muslim women about the concept of halalan toyyiban in Islam. That one should not only be concerned with what is lawful or permissible, as evident in the greater halal consciousness in Singapore (Nasir \& Pereira, 2008; Nasir et al., 2010) but also what is good, in line with what the 
Quran mentioned, 'Eat of what is on earth, lawful and good' (2:168). 'Good' here can be understood broadly as in that which is beneficial for health, the environment and also in terms of proportion, among other factors. Over recent years, there has been a significant amount of scholarly and popular works that have been produced around this concept, which focus on the Malay communities in Indonesia, Malaysia and Singapore.

\section{Influence of Traditional Gender Roles on Health}

Despite recognising the importance of maintaining a healthy lifestyle based on the Islamic precepts on health, the desire to maintain a healthy lifestyle remains an aspirational one, especially for married women. The findings show that their marital status play a significant role in influencing their lifestyle patterns. The data demonstrate that only two out of 11 respondents who are suffering or have suffered from at least one chronic illness are taking proactive measures to improve their health. Nine others who are married with children have not been living an active lifestyle despite being diagnosed with chronic conditions. Among those who have family members who are suffering from hereditary chronic diseases, only three out of five respondents are maintaining a healthy lifestyle by their own admission. Additionally, among those who neither have a history of chronic illness nor have family who have chronic conditions, only one of five women who is currently single, observe an active lifestyle. Out of the five main aspects of physical health outlined by HPB, the only good habit that most women have been observing is the avoidance of harmful substancesin conformance to the Islamic ruling that forbids Muslims to consume alcohol and toxic substances. Common reasons given by those who do not observe other aspects of health, particularly, regular physical exercises, having enough rest, and going for regular health screenings were: "Long working hours", "Work and family commitments", "Too tired to exercise", "No motivation to exercise" and "Nobody to exercise with".

Married women in paid employment attribute their lack of time to exercise to the double burden of paid labour and homemaking responsibilities that their husbands expect them to fulfil or that they assume they should fulfil by virtue of being a wife. F3, a teacher at a private education centre, and H3, a Senior Manager in a local firm, reflect such sentiments:

After working from 9am to 6pm, most of us women still have to do household chores. So where can I find the time to exercise? Sometimes, I have to work on Saturdays, which leaves me with only Sunday to rest. But Sunday is for grocery shopping. As much as I want to exercise, I just don't have the time to do so. (F3)

I'm seldom in Singapore. Always on business trips. Whenever I'm in Singapore, I try to exercise as much as possible, but this is impossible due to work schedule. Sometimes I work till late at night, leaving me with little time to exercise by the time I get home. I also have to prepare dinner for my family. (H3) 
When asked if their family members help them out in household chores, these women emphasised that it is their responsibility to manage the bulk of household duties. Some invoked Islamic concepts to justify why they are the ones assuming greater homemaking responsibilities. For example, some of them viewed the fulfilment of household responsibilities as a way of attaining pahala ('rewards in the hereafter'). Generally, their narratives do not indicate that they co-share household responsibilities with their husbands. In fact, they point to hierarchical gender relations where authority and final decision-making lie in the hands of their husbands, who are assumed to be the head of the family. Their husband's authority reinforces the traditional roles of women in the domestic realm. B2, a part-time religious teacher, and H1, a homemaker, highlight the irony of women's assumed responsibility of preparing meals, yet having little control over their process and outcomes:

We women want to use healthy ingredients like less salt and healthier cooking oil. But at the end of the day, it's my husband who decides if the food is tasty or not. If it's not up to his standard, I'll have to add more salt. I have plans to make salad for lunch but he still prefers the traditional asam pedas (Malay dish). (B2)

My husband sets the standards of the menu at home. So, I try my best to include vegetables in our meals. But sometimes, he orders fast food for the family, which goes against the healthy standards he has set for the family. (H1)

\section{'Aurat' and Exercise}

Another barrier that prevents the women from exercising regularly is the concern over the exposure of aurat when participating in rigorous physical activities in open public spaces. Aurat refers to parts of the body that Islam requires Muslims to cover to protect their modesty and moral decency. It constitutes the whole body except the face and palms for women, and the navel to the knees for men. Muslims are required to cover their aurat in the presence of their non-mahram (spouse or immediate kin). Protecting one's aurat goes beyond covering oneself. It also entails observing one's moral conduct in public. Almost all the respondents shared that the choice of location is an important consideration for them if they were to exercise in public. Contrary to newspaper reports that depict Malay women enjoying themselves while participating in all-women physical activities such as Zumba and kebayarobics (an amalgam of aerobics and traditional Malay dance movements), respondents of this study, regardless of age group, are not inclined to participate in such activities. They do not feel comfortable exercising in open areas that expose them to the watchful eyes of men. A1 and E3 represent the women's discomfort:

The reason I picked I have 'no one to exercise with' in the questionnaire is not because I don't have friends to exercise with. Of course it's more fun with friends to exercise. Actually, I don't feel comfortable exercising in public places especially jogging and Zumba, because men are watching you. (A1) There was once when I was doing Zumba at a mass event at the big open space in WGS (Wisma Geylang Serai, a cultural hub for the Malay community). 
Then I realised there was a group of pakcik-pakcik (elderly men) who was watching us and taking photos of us from the second floor. I felt very uncomfortable because they seem to be deriving pleasure from voyeurism. (E3)

\section{Discussion}

To a certain extent, the findings corroborate those of existing research that explore the role of Islam in the attitudes and beliefs of Muslim women towards their health. Findings from past research reveal that Islam plays a significant role in Muslim women's health narratives. They also highlight the central position of theological considerations that centre on religious virtues and scriptural sources in the women's belief system. These are exemplified by Ahaddour and Broeckaert's (2018) study, which examines how Moroccan Muslim women living in Antwerp, Belgium, view their health, illness and healing practices, and Vu et al.'s (2018) research that assesses the views of American Muslim women in Greater Chicago on effective strategies for mosque-based interventions to promote women's health (Ahaddour \& Broeckaert, 2018; Vu et al., 2018). Yet, there are still gaps in these studies, health intervention programmes and local community efforts that interweave Islamic concepts into messages that promote good health.

This article has identified some of these gaps based on the findings, namely, the lack of emphasis on the gendered dimensions of health and their intersections with Islamic-based health discourses. As past research has shown, health-related messages are more likely to resonate with Muslim communities when they are framed as concordant with Islamic scriptures (Ahaddour \& Broeckaert, 2018; Vu et al., 2018). While there have been a plethora of discussions by religious scholars on ways to improve the more tangible markers of health, the less overt ones embedded in Muslims' social relations are largely overlooked. Findings from this study have shown that male power in the household is so deeply entrenched that they affect the dayto-day routines of women and account for their limited time to rest and engage in physical activities. The high level of physical and mental exhaustion experienced by many Malay women as a result of their domestic roles reflects trends in dual-income households in developed countries where both parents take up paid employment. In Singapore, the labour force participation rate (LFPR) of Malay women in full employment is $50 \%$ as compared to $55.8 \%$ for all local women (Housing Development Board, 2013). ${ }^{2}$ Although the LFPR of Malays in general has always been lower than other ethnic groups, Association of Muslim Professionals Singapore (AMP) reported that the LFPR among Malays has increased over the years, including that of Malay women (Association of Muslim Professionals, 2017). ${ }^{3}$ This is parallel to the increasing trend of women entering the workforce at the national level. While the

\footnotetext{
2 This data from 2013 only includes those living in public housing (80 per cent of the local population). Data on LFPR provided by Singapore Department of Statistics do not stratify by ethnicity.

3 AMP is a non-partisan organisation established by professionals to advance the needs of the Malay community.
} 
LFPR for women aged 25 to 64 was $63.9 \%$ in 2009, it increased to $73.3 \%$ in 2019. For women aged 65 and above, it increased from $8.9 \%$ to $19.6 \%$ within the same period (Ministry of Manpower, 2019). These statistics do not take into account the activities of Malay-Muslim women who immerse themselves in home-based businesses which are popular among the community. In 2020, the restrictions placed on home-based businesses by the government because of the COVID-19 pandemic faced a huge pushback from the Malay populace because of their perceived unevenness, which led to the state rolling back on some of its measures.

Gender inequalities still exist in the labour market whether or not they are documented by official statistics. Traditional gendered roles where men are the main breadwinner while women are responsible for the bulk of household chores and caregiving duties persist. Sociologist Arlie Hochschild has argued that despite more women entering the workforce, they are caught in a stalled revolution since traditional gender roles and workplace policies continue to place caregiving and childminding duties on them (Hochschild \& Machung, 2012). In Singapore, some women are still not paid equally as their male counterparts for the same position. A recent study conducted by Ministry of Manpower (MOM) reported that local women earn $6 \%$ less than men when considering adjusted gender pay gap, and $16.3 \%$ less when comparing the median pay gap in 2018 (Ministry of Manpower, 2020). Although the number of women entering tertiary institutions is almost the same as men, women in their $30 \mathrm{~s}$ tend to drop out of employment due to child-rearing and caregiving responsibilities (Liang-Lin, 2015). An MOM report noted that $67.9 \%$ of female residents outside the labour force cited 'family responsibilities' and 'housework' as the main reason for not working and not looking for a job compared to only $4.4 \%$ of male residents who cited the same reasons (Ministry of Manpower, 2019).

Academics have also highlighted the unequal distribution of workload in household and caregiving roles between men and women. In her 2010 article on family policies in Singapore, Teo argues that state policies presume that women are inextricably linked to their families- that the responsibilities of building families, maintaining households and caregiving lie on women's shoulders. They are simultaneously encouraged to contribute to the national economy through formal employment (Teo, 2010). The way these ideals are translated into policies differ by gender, as evident from the discrepancy in benefits provided by employees when they have babies, for instance. While employers of women who have given birth are required to provide 16 weeks of paid maternity leave, men receive only two weeks of paternity leave, assuming their employers choose to share the costs of leave between themselves and the state. Previously, men only received up to three days of leave. Thus, such policies suggest that caregiving responsibilities remain a woman's domain.

The above phenomena are not unique to Singapore. They are also prevalent in other developed countries where dual income households are common. For example, del Mar García-Calvente et al. (2012) qualitative study, which analyses perceptions of men and women in Granada, Spain towards their health, vulnerability and coping levels with illness also demonstrates unequal gender relationships among married couples and how these influenced the way they perceive their health. Just like in Singapore, Spanish women continue to take greater responsibility for informal care than men despite a higher political commitment towards gender equality (del Mar 
García-Calvente et al., 2012). The asymmetrical power relationships appear to affect women from the less privileged class even more, with most of them describing their health negatively due to the burden of having to take on greater household responsibilities with some even suffering physical violence at the hands of their partners (del Mar García-Calvente et al., 2012). Similarly, Pietilä and Rytkönen's (2008) research on how ordinary Russians conceptualize and account for gender difference in life expectancy highlights that there are few alternatives to conventional discourses and understandings of gender relations in contemporary Russia despite profound social transformations.

Similarly, hierarchical gender relations are maintained in Singaporean Muslim households, not only in the name of preserving Malay culture, but also when religious concepts are invoked indiscriminately to justify patriarchy or to reinforce the notion of the "ideal" Malay-Muslim wife. The caregiving duties of the mother and wife are often emphasised as religious contributions and acts of piety when many of these duties also apply to men. Malay-Muslim women would often internalize these discourses out of the fear of transgressing religious precepts even though these may not be the correct religious understanding or even if it be to the detriment of their health, as findings from this research have shown. This explains why many Muslim women's understanding of health from an Islamic perspective remains tenuous and why they are unconfrontational when facing issues that fall beyond the more explicit Islamic-based identifiers, such as those referring to halalness or permissibility, despite their adverse consequences on their health.

Additionally, the fact that none of our research participants employs a domestic helper is significant especially in the context of Singapore where hiring foreign domestic workers is very common. Studies have highlighted that those households that employ waged domestic labour tend to be those that are more affluent and in which both the husband and wife are engaged in full-time formal employment (Huang \& Yeoh, 1996; Teo, 2010). Local women who participate in the workforce would in turn transfer their previous subordination onto their hired help, who are mostly women from developing countries in Asia such as Indonesia and the Philippines, thereby perpetuating the patriarchal ideology of housework as women's work and of housework as non-work (Huang \& Yeoh, 1996). It is unlikely that our respondents do not engage with domestic labour because of socio-economic reasons given that they were chosen across a spectrum of social class background. There is also no available statistics on families that employ domestic helpers based on race or religion. What is apparent however, is that without any assistance with domestic work, Malay-Muslim women have ended up feeling more exhausted and having less time and mental energy to make healthier choices for themselves and their families. Thus, this reiterates our earlier point that the association between poor health outcomes and the cultural norms and practices of the Malay community is a problematic one.

Gender power relations are also reflected in our findings pertaining to the concerns regarding exercising in public spaces. The struggle for Muslim women to protect their 'aurat' and the discomfort that they experience when exercising in public spaces is framed in the context of perceived male predation as they attempt to express a moral self that is in line with the teachings of Islam. This contrasts with 
how men are able to navigate more freely in public spaces without compromising their religiosity and still maintaining respectability. Furthermore, while there is general agreement that 'aurat' for men is to cover from navel to knees, there are several conditions that constitute 'aurat' for women such as covering with non-fitting clothes that do not reveal the body shape. The responsibility of having to negotiate the preservation of modesty and pursuing physical activity may cause Muslim women to refrain from exercising in public spaces.

The issue on voyeurism is also a pertinent one and underscores the need for society to implement measures that protect women. Our respondents' experience with voyeurism is not an isolated one. Cases on outrage of women's modesty have been on the rise in the broader community, ranging from male university students secretly filming videos of female students showering in university hostels, to men taking upskirt videos and photos of scantily clad women in public places. The number of cases increased from 1396 in 2011 to 1728 in 2018 (Singapore Department of Statistics, 2020b; Wong, 2019). Hence, the fear of over-exposing themselves in public through exercises that involve rigorous movements is a legitimate concern of Muslim women, especially when the definition of aurat in Islam encompasses the observance of both physical and moral decency. This also explains why Malay men are more active in sports than women (Ang, 2018).

\section{Conclusion}

This article has paved the way for the bridging of gaps between current Islamicbased health discourses and the barriers to optimising women's health outcomes. One way is by invoking religious concepts and narratives to improve gender relations in ways that can contribute positively to women's health. These include citing stories of how Prophet Muhammad and his wife co-share their domestic and familial responsibilities, which will free up exercise and recreational time for women. Another way is to educate men to be more respectful of women especially towards those who are utilising public spaces that offer them the opportunities to exercise. The Quran contains many empowering verses on gender equality and respect for women, which can be leveraged in healthcare discourses. However, these are seldom brought to the fore of discussions on health and illness since Islamic laws and guidelines are mostly governed by men. Therefore, this study bears important implications for Islamic-based and gender-based health promotion programmes and interventions that promote the well-being of Muslim communities. The findings suggest that it may be useful to frame the barriers faced by Muslim women that prevent them from optimising their health outcomes as a social issue rather than just an individual one. Reconceptualising them this way will extend the responsibility of improving women's health from the individual to the community.

This article acknowledges that there are limitations to this study, including the small sample size. A larger sample may reveal the influence of income on lifestyle habits. However, the research only focuses on individual narratives for an in-depth analysis of attitudes and practices rather than generalising the findings to broader patterns of the behaviour and perceptions of Muslim women from Southeast Asia 
or other parts of the world. Nonetheless, this study has reinforced the importance of incorporating women's voices in health research, particularly on Muslim communities. This is especially salient in the context of the Malay world given that religious discourses can still be very patriarchal. The notion of gendered hierarchies within the domestic sphere is still being upheld by local Islamic preachers, males and females alike (Nurhaizatul, 2016). Uncovering local Muslim women's lived experiences, especially the challenges they face in balancing time to exercise and to manage their daily household chores, as well as the limited power they have in decisionmaking processes within the realm of the home, bring to the fore the adverse effects these have on their health. A useful line of future research would be to explore other female-friendly strategies that can help alleviate women's burden at home and at work. Another potential area of study could involve exploring how society and gender advocacy groups can create safe spaces where women feel comfortable exercising in public without the fear of voyeurism. There is nothing more empowering than establishing spaces that are provided by women for women.

\section{Data availability statement}

The data are available from the corresponding author upon reasonable request.

Acknowledgements The authors would like to thank their research assistant, Nurul Insyira, for her assistance in data collection.

Authors' Contributions All authors contributed to the study conception and design. The first draft of the manuscript was written by the first author. All authors read and approved the final manuscript.

Funding The authors received no financial support for this study.

Code availability Not applicable.

Declarations

Ethics statement The procedures used in this study adhere to the tenets of the Declaration of Helsinki.

Informed Consent Informed consent was obtained from all individual participants included in the study. Participants signed informed consent regarding publishing their data.

Conflict of interest No potential conflict of interest was reported by the authors.

\section{References}

Abbas, A. N. b. (2012). The Islamic Legal System in Singapore Pac. Rim L. \& Pol'y J., 21, $163-187$. https://digitalcommons.law.uw.edu/cgi/viewcontent.cgi?article $=1607 \&$ context $=$ wilj

Aboul-Enein, B. H. (2016). Health-promoting verses as mentioned in the Holy Quran. Journal of Religion and Health, 55(3), 821-829.

Ahaddour, C., \& Broeckaert, B. (2018). "For Every Illness There is a Cure": Attitudes and Beliefs of Moroccan Muslim Women Regarding Health, Illness and Medicine. Journal of Religion and Health, 57(4), 1285-1303. 
AlKhayat, M. H. (1997). Health: An Islamic perspective. World Health Organization.

Ang, S. (2018). Social participation and mortality among older adults in Singapore: Does ethnicity explain gender differences? The Journals of Gerontology: Series B, 73(8), 1470-1479.

Ashy, M. A. (1999). Health and illness from an Islamic perspective. Journal of Religion and Health, 38(3), 241-258.

Association of Muslim Professionals. (2017). Demographic Study on Singapore Malays. Retrieved 1 May 2020 from https:/www.amp.org.sg/wp-content/uploads/2017/06/12-Section-9_Demographic-Study. pdf

Bahar, Z., Okçay, H., Özbıçakçı, Ş, Beşer, A., Üstün, B., \& Öztürk, M. (2005). The effects of Islam and traditional practices on women's health and reproduction. Nursing Ethics, 12(6), 557-570.

Chang, A.-L. (2010, 13 March 2010). Malays \& Obesity. The Straits Times. https://www.yumpu.com/en/ document/read/12192034/malays-obesity-big-trouble-nuh

del Mar García-Calvente, M., Hidalgo-Ruzzante, N., del Río-Lozano, M., Marcos-Marcos, J., MartínezMorante, E., Maroto-Navarro, G., Mateo-Rodríguez, I., \& Gil-García, E. (2012). Exhausted women, tough men: A qualitative study on gender differences in health, vulnerability and coping with illness in Spain. Sociology of Health \& Illness, 34(6), 911-926.

Du Bois W.E.B. [1899] 1967. The Philadelphia Negro: A Social Study. New York: Schocken Books.

Zakaria, F., \& Zainal, H. (2017). Traditional Malay Medicine in Singapore: A Gramscian perspective. Indonesia and the Malay World, 45(131), 127-144.

Hochschild, A., \& Machung, A. (2012). The second shift: Working families and the revolution at home. Penguin Group.

Housing \& Development Board. (2013). Public Housing in Singapore: Residents' Profile, Housing Satisfaction and Preferences. HDB Sample Household Survey 2013. Retrieved 1 May 2020 from https:// www.hdb.gov.sg/cs/infoweb/-/media/doc/PLG/monograph-1-29-dec-2014.pdf

Huang, S., \& Yeoh, B. S. A. (1996). Ties that bind: State policy and migrant female domestic workers in Singapore. Geoforum, 27(4), 479-493.

Zainal, H. (2012). Reviving Singaporean-Malay cultural identity through health tourism: A case study of traditional Malay medical practitioners in Singapore's Geylang Serai. International Journal of Arts \& Sciences, 5(6), 241-257.

Nasir, K. M., \& Pereira, A. (2008). Defensive Dining: Notes on the Public Dining Experiences in Singapore. Contemporary Islam, 2(1), 61-73.

Nasir, K. M., Pereira, A., \& Turner, B. S. (2010). Muslims in Singapore: Piety, Politics and Policies. Routledge.

Khoo, H. S., Lim, Y. W., \& Vrijhoef, H. J. (2014). Primary healthcare system and practice characteristics in Singapore. Asia Pacific Family Medicine, 13(1), 8.

Kiong, T. C. (2008). Religious trends and issues in Singapore. In L. A. Eng (Ed.), Religious diversity in Singapore (Vol. 28, pp. 184-203). Institute of Southeast Asian Studies.

Koenig, H.G. \& Al Shohaib, S. (2014). 'Beliefs about health, healing and healthcare' In Health and wellbeing in Islamic societies: Background, research and applications, 43-56. Cham, Heidelberg, New York, Dordrecht, London: Springer

Liang, E. W., Daniel, P., Sim, A., Lee, R., Tay, S. M., Luo, N., \& Koh, G.C.-H. (2018). Health-related quality of life in a low-socioeconomic status public rental-flat population in Singapore. Applied Research Quality Life, 13, 179-195.

Liang-Lin, T. (2015). Five gender gaps Singapore women still face in 2015. The Straits Times. https:// www.straitstimes.com/opinion/five-gender-gaps-singapore-women-still-face-in-2015

Ministry of Health. (2010). National Health Survey 2010. Epidemiology \& Disease Control DIvision. Retrieved 1 May 2020 from https:/www.moh.gov.sg/docs/librariesprovider5/resources-statistics/ reports/nhs2010---low-res.pdf

Ministry of Health. (2020). Providing accessible, affordable and good quality healthcare. Ministry of Health. Retrieved 1 May 2020 from https:/www.moh.gov.sg/docs/librariesprovider5/cos2020/cos2020---providing-accessible-affordable-and-good-quality-healthcare.pdf

Ministry of Manpower. (2019). Labour Force in Singapore 2019. Retrieved 1 May 2020 from https:// stats.mom.gov.sg/iMAS_PdfLibrary/mrsd_2019LabourForce_survey_findings.pdf

Ministry of Manpower. (2020). Singapore's Adjusted Gender Pay Gap Narrows to 6\%. Retrieved 1 May 2020 from https://stats.mom.gov.sg/Pages/Singapores-Adjusted-Gender-Pay-Gap.aspx

MOH, \& HPB. (2014). Healthy Living Master Plan. Ministry of Health, 
National Registry of Diseases Office. (2019). Singapore Myocardial Infarction Registry Annual Report 2017. Health Promotion Board. Retrieved 1 May 2020 from https://www.nrdo.gov.sg/docs/librariesp rovider3/default-document-library/smir-web-report-2017.pdf?sfvrsn=14c16d4f_0

Nazroo, J. Y. (1998). Genetic, cultural or socio-economic vulnerability? Explaining ethnic inequalities in health. Sociology of Health \& Illness, 20(5), 710-730.

Jamil, N. (2016). You are my garment: Muslim women, religious education and self-transformation in contemporary Singapore. Asian Studies Review, 40(4), 545-563.

Padela, A. I., Killawi, A., Heisler, M., Demonner, S., \& Fetters, M. D. (2011). The Role of Imams in American Muslim Health: Perspectives of Muslim Community Leaders in Southeast Michigan. Journal of Religion and Health, 50, 359-373.

Palència, L., Malmusi, D., De Moortel, D., Artazcoz, L., Backhans, M., Vanroelen, C., \& Borrell, C. (2014). The influence of gender equality policies on gender inequalities in health in Europe. Social Science \& Medicine, 117, 25-33.

Pietilä, I., \& Rytkönen, M. (2008). 'Health is not a man's domain': Lay accounts of gender difference in life-expectancy in Russia. Sociology of Health \& Illness, 30(7), 1070-1085.

Prime Minister's Office Singapore. (2017). National Day Rally 2017. Retrieved 1 May 2020 from https:// www.pmo.gov.sg/Newsroom/national-day-rally-2017

Rai, R. K. (2015). Utilization of maternal health-care services by Muslim women in India, Bangladesh, and Pakistan, 2005-2007. Journal of Public Health, 23(1), 37-48.

Rajaram, S. S., \& Rashidi, An. (2003). African-American Muslim Women and Health Care. Women \& Health, 37(3), 81-96.

Razee, H., Van Der Ploeg, H. P., Blignault, I., Smith, B. J., Bauman, A. E., McLean, M., \& Wah Cheung, N. (2010). Beliefs, barriers, social support, and environmental influences related to diabetes risk behaviours among women with a history of gestational diabetes. Health Promotion Journal of Australia, 21(2), 130-137.

Sabanayagam, C., Shankar, A., Saw, S. M., Tai, E. S., \& Wong, T. Y. (2009). The association between socioeconomic status and overweight/obesity in a Malay population in Singapore. Asia Pacific Journal of Public Health, 21(4), 487-496.

Sandelowski, M. (2000). Whatever happened to qualitative description? Research in Nursing \& Health, 23(4), 334-340.

Shaw, T., Ishak, D., Lie, D., Menon, S., Courtney, E., Li, S. T., \& Ngeow, J. (2018). The influence of Malay cultural beliefs on breast cancer screening and genetic testing: A focus group study. PsychoOncology, 27(12), 2855-2861.

Singapore Department of Statistics. (2019). Population Trends. Retrieved 1 May 2020 from www.sings tat.gov.sg

Singapore Department of Statistics. (2020a). Population and Population Structure. Retrieved 1 May 2020 from https://www.tablebuilder.singstat.gov.sg/publicfacing/selectVariables.action

Singapore Department of Statistics. (2020b). Public Safety: Crimes and Offences. Singapore Police Force. Retrieved 1 May 2020 from https://www.tablebuilder.singstat.gov.sg/publicfacing/createData Table.action?refId $=15648$

Tan, S. T., Quek, R. Y. C., Haldane, V., Koh, J. J. K., Han, E. K. L., Ong, S. E., Chuah, F. L. H., \& Legido-Quigley, H. (2019). The social determinants of chronic disease management: Perspectives of elderly patients with hypertension from low socio-economic background in Singapore. International Journal for Equity in Health, 18(1), 1.

Tang, S., \& Brown, A. (2008). 'Race' matters: Racialization and egalitarian discourses involving Aboriginal people in the Canadian healthcare context. Ethnicity and Health, 13(2), 109-127.

Teo, Y. (2010). Shaping the Singapore family, producing the state and society. Economy and Society, 39(3), 337-359.

The Straits Times. (2019, 27 Sep 2019). First woman in Fatwa Committee as full member. The Straits Times. https://www.straitstimes.com/singapore/first-woman-in-fatwa-committee-as-full-member

Tober, D. M., \& Budiani, D. (2007). Introduction: Why Islam, health and the body? Body \& Society, 13(3), 1-13.

Vu, M., Muhammad, H., Peek, M. E., \& Padela, A. I. (2018). Muslim women's perspectives on designing mosque-based women's health interventions - an exploratory qualitative study. Women \& Health, 58(3), 334-346.

Wee, L. E., Lim, L. Y., Shen, T., Lee, E. Y., Chia, Y. H., Tan, A. Y. S., \& Koh, G.C.-H. (2014). Choice of primary health care source in an urbanized low-income community in Singapore: A mixed-methods study. Family Practice, 31(1), 81-91. 
Wong, P. T. (2019, 30 April 2019). The big read: Singapore's voyeurism problem- what's wrong with men, or the world? Channel News Asia. https://www.channelnewsasia.com/news/singapore/singa pore-voyeurism-problem-spy-cam-sex-harassment-monica-baey-11487244

Wong, P. T., \& Toh, E. M. (2017, 25 August 2017). War on diabetes: Changing eating habits of Malay, Indian communities an uphill task. Today Online. https://www.todayonline.com/singapore/war-ondiabetes-changing-eating-habits-of-malay-indian-communities-an-uphill-task

World Health Organisation. (2020). Constitution of the World Health Organization. Retrieved 1 May 2020 from https://www.who.int/about/who-we-are/constitution

World Health Organization. (2013). Women's health in Islam: addressing harmful traditional practices. . Retrieved 1 May 2020 from http://www.emro.who.int/media/news/womens-health-inislam-consu ltation.html

Publisher's Note Springer Nature remains neutral with regard to jurisdictional claims in published maps and institutional affiliations. 